13 - ORIGINAL ARTICLE

ISCHEMIA-REPERFUSION

\title{
Heart injury following intestinal ischemia reperfusion in rats is attenuated by association of ischemic preconditioning and adenosine ${ }^{1}$
}

\author{
Micaela Frasson Montero', Rafael Saurim ${ }^{\mathrm{II}}$, Wesley Guedes Sava Bonservizi ${ }^{\mathrm{II}}$, Marcia Kiyomi Koike ${ }^{\mathrm{III}}$, Murched Omar Taha ${ }^{\mathrm{IV}}$ \\ DOI: http://dx.doi.org/10.1590/S0102-8650201400140013 \\ ${ }^{I}$ Medical student at ABC Medical School, Santo André, SP, Brazil. Scientific Initiation Project. Data acquisition, analysis and interpretation of data, \\ responsible for manuscript writing. \\ ${ }^{I I}$ Medical student at Federal University of São Paulo - UNIFESP, São Paulo, SP, Brazil. Data acquisition, analysis and interpretation of data, responsible \\ for manuscript preparation. \\ IIIPhD, Laboratory of Emergency Medicine - LIM-51, Faculty of Medicine of São Paulo University, Sao Paulo, Brazil. Interpretation of data, \\ histopathological, statistical analysis and critical revision. \\ ${ }^{\text {IV }} \mathrm{PhD}$, Associate Professor, Operative Technique and Experimental Surgery Division, Department of Surgery, UNIFESP, Sao Paulo, Brazil. Main \\ author. Responsible for conception, design, intellectual and scientific content of the study. Final approval of the version to be published.
}

\section{ABSTRACT}

PURPOSE: To investigate the effect of ischemic preconditioning (IPC) and adenosine as strategies to protect cardiac injury caused by intestinal IR in rats, based on increasing in adenosine bioavailability and improvement of cell energy state by IPC.

METHODS: Male Wistar rats were submitted to 60 minutes of intestinal ischemia and 120 minutes of reperfusion. Intravenous injections of saline or Adenosine (AD) was administered five minutes before ischemia, five minutes before reperfusion and after 55 minutes reperfusion. Cardiac samples were obtained, fixed in formalin solution, embedded in paraffin, and sections of $5 \mu \mathrm{m}$ were stained by hematoxylin-eosin. Histological analysis of myocardium was performed according occurrence of necrosis signs: piknosis, band contraction, eosinophilic cytoplasm, karyorrhexis and vacuolization (score - zero to 5).

RESULTS: The groups submitted to ischemia alone $(\mathrm{I}=4.0)$, and reperfusion $(\mathrm{IR}=4.5)$ showed highest level of lesion compared to the others $(I+I P C=3.3, I R+I P C=3.6, I+A D=3.0, I R+A D=3.8)$. The most interesting result was association of $I P C$ and $A D$ in $I R$ model ( $\mathrm{IR}+\mathrm{IPC}+\mathrm{AD}=1.2, \mathrm{p}=0.002$ ), showing preservation of the heart tissue, with fibers showing typical cross-striations and nuclei characteristics. Rare and small areas of tissue necrosis was observed and suggestion of capillaries congestion.

CONCLUSION: Intestinal ischemia reperfusion promotes cardiac tissue injury. Ischemic preconditioning in association with adenosine is an efficient strategy to protect the heart against ischemia and reperfusion injury.

Key words: Adenosine. Ischemic preconditioning. Intestinal ischemia/reperfusion. Heart. Rats. 


\section{Introduction}

The cellular death can be promoted by severe circulatory alterations and it has been considered a problem morphological and functional organs recovery after transplantation or in acute tissue injury ${ }^{1}$. Morbidity and mortality rates due to ischemia and reperfusion injuries encouraged the researchers involved in transplantation, emergency procedures and major surgeries to investigate strategies to maintain structural and functional organ integrity ${ }^{2}$.

In ischemic conditions, organs has its oxygen and metabolic substrates supplies reduced temporarily, accumulating metabolites and other cell toxins, and during reperfusion, massive releasing of oxygen free radicals promotes worsening of the tissue injury.

The oxygen free radicals have an important role in lipid peroxidation, compromising cellular membrane and organelles, such as mitochondria with damage and cellular destruction ${ }^{3}$.

In small bowel transplantation or during resuscitation, gut ischemia and reperfusion may result in severe impairment of the intestinal microcirculation, resulting in mucosal damage, intestinal barrier dysfunction, bacterial translocation, systemic inflammation, multiple organ failure and death ${ }^{4}$. The multiple organ failure is an important aspect of the remote sites of harmful effects of oxygen free radical. In this way, drugs and cellular protector strategies to prevent or to attenuate systemic organ dysfunction must be investigated. Many types of strategies has been studied ${ }^{5-11}$, such as exogenous Adenosine treatment ${ }^{12-16}$ and ischemic preconditioning ${ }^{17-21}$.

Adenosine is anucleotide,ATPmetabolite, and itshows action in cellular homeostasis regulation and it is produced in major amount in ischemic conditions. It reduces cytokine synthesis, inflammation intensity and platelet aggregation. Moreover, it stimulates production of antioxidant enzymes, induces and actives superoxide dismutase enzyme, nitric oxide synthase and, consequently, induces production of nitric oxide, to reduce oxidative stress ${ }^{12}$.

Experimental study of ischemia and reperfusion injury showed that adenosine reduces cellular death occurrence due to modulation of cardiac response to stress ${ }^{13}$.

The ischemic preconditioning has been pointed as potential therapeutic strategy, promoting tissue tolerance to ischemia and reperfusion injuries. The IPC involves different mechanisms, such as releasing of adenosine, nitric oxide, hemeoxygenase and protein kinase $\mathrm{C}^{19-21}$. Several organs respond to exposure of brief periods of IR, increasing resistance to subsequent cytotoxic, longer duration and aggressiveness, stimulus ${ }^{22}$.
Ischemia and reperfusion induce morphological changes that can affect the patient prognosis. Some studies have been done using different strategies to minimize the tissue damage, as ischemic preconditioning and adenosine. Considering that ischemic preconditioning induces increase in adenosine release and improves cell energy state, the aim of this study was to investigate the effect of both strategies on the heart injury caused by intestinal ischemia and reperfusion in rats.

\section{Methods}

This study protocol was approved by Research Ethics Committee, Federal University of São Paulo (UNIFESP) (number 1815/08). The surgical procedures were performed in Experimental Microsurgical Laboratory, Operative Technique and Experimental Surgery Division, Medical School of the UNIFESP and the histopathological analysis at the Laboratory of Surgical Physiopathology (LIM-62), Faculty of Medicine of the University of São Paulo.

Adult Male EPM-1 Wistar rats were used ( $\mathrm{n}=54$, Rattus norvegicus albinus, Rodentia, Mammalia), weighing between $250 \mathrm{~g}$ and $300 \mathrm{~g}$. Rats were come from Center for experimental models development in medicine and biology of the UNIFESP.

All animals were handled according to the ethical principles of laboratory animal care. The animals were kept in a vivarium for 48 hours for observation and adaptation, where they received water and balanced food ad libitum and were kept in appropriate cages, with a maximum of five animals per cage, under controlled conditions for light, temperature, and daily hygiene.

Animals were randomly assigned into nine groups $(n=6$, each group) according to the treatments: saline (Sham), adenosine (AD) or ischemic preconditioning (IPC) and procedures of intestinal ischemia (I) or intestinal ischemia and reperfusion (IR) or Sham group (Figure 1).

\begin{tabular}{|l|c|c|c|}
\hline & $\begin{array}{c}\text { Ischemic } \\
\text { Preconditioning }\end{array}$ & $\begin{array}{c}\text { Adenosine } \\
\text { or } \\
\text { Saline }\end{array}$ & $\begin{array}{c}\text { Ischemic } \\
\text { Preconditioning } \\
+ \text { Adenosine }\end{array}$ \\
\hline Ischemia & $\mathrm{IPC}+\mathrm{I}$ & $\mathrm{AD}+\mathrm{I}$ & $\mathrm{IPC}+\mathrm{AD}+\mathrm{I}$ \\
\hline $\begin{array}{l}\text { Ischemia and } \\
\text { Reperfusion }\end{array}$ & $\mathrm{IPC}+\mathrm{IR}$ & $\mathrm{AD}+\mathrm{IR}$ & $\mathrm{IPC}+\mathrm{AD}+\mathrm{IR}$ \\
\hline Sham & - & Saline & - \\
\hline
\end{tabular}

FIGURE 1 - Schematic representation of the experimental groups according to treatment: saline (Sham), adenosine (AD) or ischemic preconditioning (IPC) in intestinal ischemia (I) model, intestinal ischemia and reperfusion (IR) model or sham procedure ( $\mathrm{n}=6$ animals, each). 
For the surgical procedure, the animals were fasted for six hours, weighed and anesthetized with an intramuscular injection of ketamine $10 \%$ (60mg.kg-1) and xylazine $2 \%$ (10mg. kg-1). The animals were considered anesthetized when they were unresponsive to mechanical stimuli, being unable to withdraw the hind limb after pain stimulus and also presented absence of palpebral reflexes. Additional doses of anesthesia were administered approximately every $50 \mathrm{~min}$. The animals were also kept well ventilated at room temperature.

The animals were placed on a constantly heated plate $\left(37^{\circ} \mathrm{C}\right)$ in supine position with hind limbs immobilized and adhesive tape across the chest. Trichotomy was performed on the right anterior cervical and right inguinal regions with a razor blade followed by antisepsis of the operative area with iodine polyvinylpyrrolidone tincture.

A neck's skin incision was made, with dissection, isolation, and catheterization of the right femoral vein to drug or saline administration. Adenosine solution (15 mg/kg) was administered five minutes before ischemia, and in IR groups, adenosine was administered five minutes before and 55 minutes after the beginning of reperfusion, again. Saline treated groups received same volume at the same intervals.

Longitudinal midline laparotomy was performed, starting below the xiphoid process in cranio-caudal direction, with dieresis of anatomical planes. The dissection of mesenteric artery was made under the surgical microscope (16-fold increase) and microsurgical instruments. In I and IR groups, the proximal mesenteric artery was isolate at its origin with mononylon 6-0.

To induce ischemic preconditioning, in the IPC group animals, the intestinal flow was interrupted for five minutes, through occlusion of the mesenteric artery using a vascular microclamp. After the temporary initial insult, the clamp was removed and the small intestine reperfused for 10 minutes. The ischemic preconditioning was performed immediately before a 60 minutes ischemia. In IR groups, reperfusion interval was 120 minutes. Sham group was anethetized, submitted to laparotomy and observed by 180 minutes. At the end, the animals were euthanized by exsanguination and the heart was removed for histological analysis.

The heart fragments were fixed in $10 \%$ buffered formaldehyde and embedded in paraffin to cut into four micra sections. Tissue sections were stained with hematoxylin-eosin (HE) for subsequent morphological analysis. The morphological analysis was performed using a light microscope from Carl Zeiss, with objectives of $400 \mathrm{X}$ for characterization and description of each histological section. On histologic examination, the myocardium lesions were classified according to the presence of: band contraction, pyknosis, hypereosinophilia, cariorrexis, cellular vacuolization and edema or presence of inflammation.

Each myocardium receives values from 1 to 5 according to the following criteria:

0 - injury absent; 1 - Mild (band contraction and dispersed pyknosis); 2 - mild-moderate (band contraction and pyknosis and dispersed cariorrexia); 3 - moderate (band contraction, pyknosis, dispersed hypereosinophilia, cariorrexia); 4 - moderate-heavy (band contraction, pyknosis, hypereosinophilia, cariorrexis, cellular vacuolization); 5 - Intense (band contraction, pyknosis, hypereosinophilia, and cariorrexis, cellular vacuolization and edema/inflammation).

Data are expressed as mean \pm SEM and comparison among groups were analyzed using One-way analysis of variance (ANOVA) and Tukey as post-hoc test. The level of rejection of the null hypothesis was set at $0.05(\mathrm{P}<0.05)$.

\section{Results}

The morphological evaluation of cardiac tissue showed no lesion in Sham group (Zero) and high level of injury in the I (4.0) and $\mathrm{IR}(4.5)$ groups. The adenosine $(\mathrm{AD}+\mathrm{I}=3.0 ; \mathrm{AD}+\mathrm{IR}=3.8)$ and $\mathrm{IPC}(\mathrm{IPC}+\mathrm{I}=3.3 ; \mathrm{IPC}+\mathrm{IR}=3.6)$ attenuated the injury provoked by ischemia as well as reperfusion. However, the reduction was relevant when both strategies were associated $(\mathrm{IPC}+\mathrm{AD}+\mathrm{I}=2.3$; $\mathrm{IPC}+\mathrm{AD}+\mathrm{IR}=1.2, \mathrm{P}<0.05$ vs I or IR) (Figure 2), as observed that the heart tissue was preserved, with fibers showing typical crossstriations and nuclei characteristic. The blood capillaries were congested, and it can see rare and small areas of tissue necrosis. Tissue aspects are illustrated in photomicrographs (Figures 3-6).

CARDIAC TISSUE INJURY LEVEL

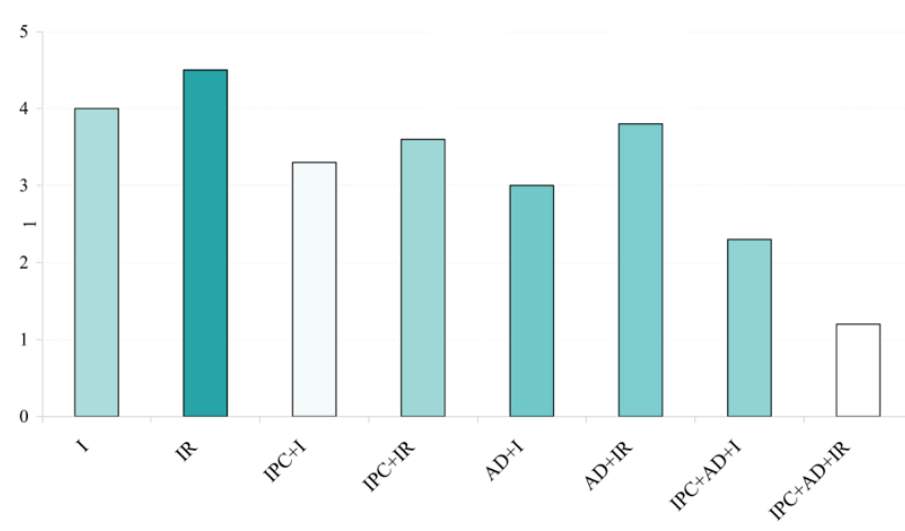

FIGURE 2 - The cardiac tissue injury scores in rats submitted to intestine ischemia (I) or ischemia and reperfusion (IR) associated or not to the treatment with Adenosine (AD) and/or ischemic preconditioning (IPC), according to the morphological evaluation. 


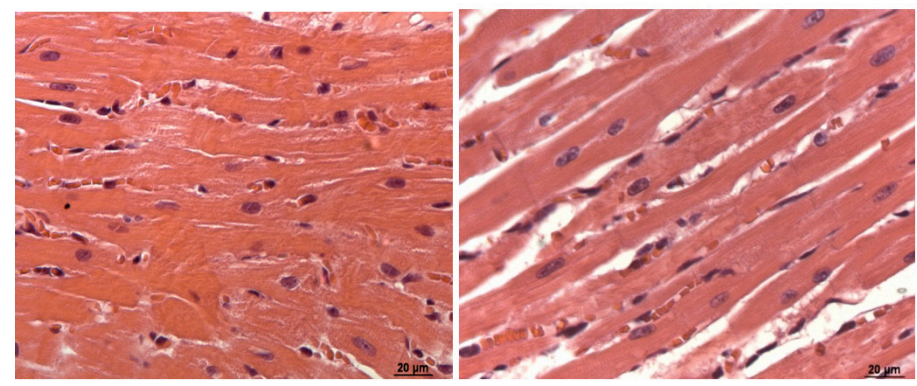

FIGURE 3 - Photomicrographs of the cardiac tissue from ischemia groups (left) and ischemia and reperfusion injury group (right). HE, 40x objective. Observe derangement of myocardium fibers after reperfusion.
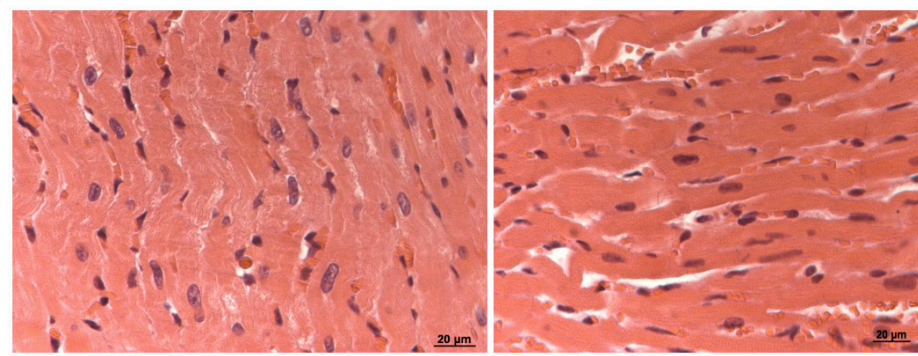

FIGURE 4 - Photomicrographs of the cardiac tissue from rats submitted to Ischemic preconditioning and ischemia (left) and Ischemic preconditioning and Ischemia e Reperfusion (right). HE, 40x objective. Observe band contraction in myocardium in both situations.

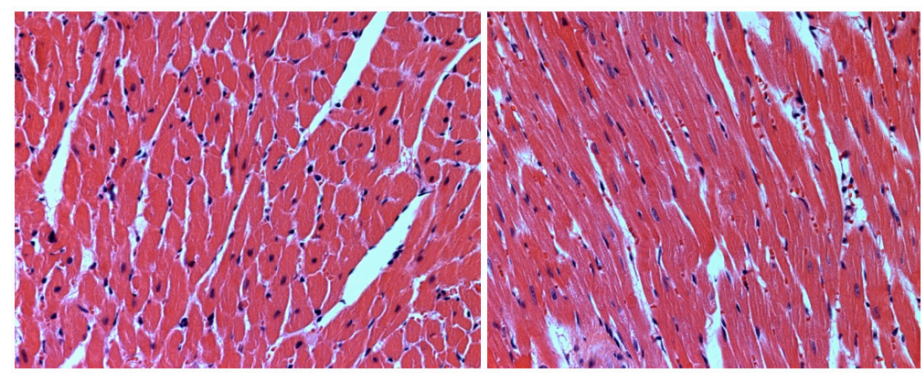

FIGURE 5 - Photomicrographs of the cardiac tissue rats submitted to intestinal ischemia and pretretated with Adenosine (left) and to intestinal ischemia and reperfusion with same treatment (right). HE, 40x objective. Observe presence of edema and band contraction.
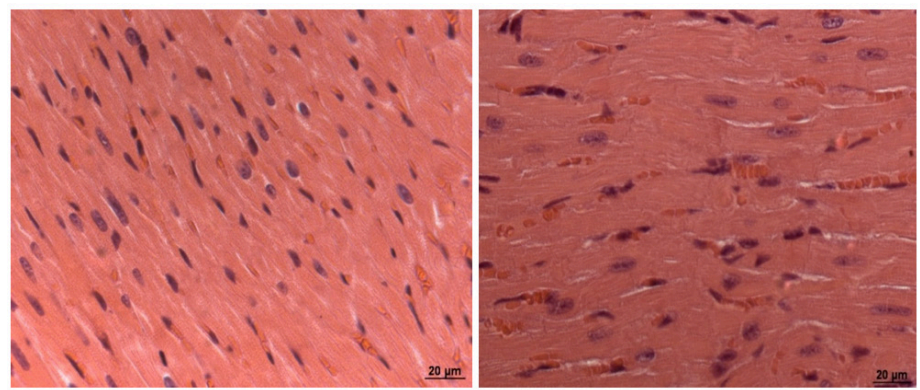

FIGURE 6 - Photomicrographs of the cardiac tissue from rats submitted to intestinal ischemia and pretreated with association of adenosine and ischemic preconditioning (left) and to same pretreatment and intestinal ischemia and reperfusion injury (right). HE, 40x objective. Observe that myocardium is preserved.

\section{Discussion}

The major contribution of the present study was to show the synergistic protective effect of the rat cardiac tissue, promoted by the association of IPC and AD, in an intestinal IR rat model. The cellular protection promoted by adenosine seems to be due to the activation of different subtypes of $\mathrm{G}$ proteins coupled receptors and its relationship of those with ATP dependent mitochondrial potassium channels, protein kinase $\mathrm{C}$ and mitogen activated protein kinase ${ }^{15,16}$. This idea is strengthened by the known effect of adenosine preconditioning, mediated by $\mathrm{A}_{1}$ $\mathrm{AR}$ receptors, before organ ischemia, and this process has been described by the tolerance to injury arising from myocardial ischemia, in the early and late stages ${ }^{13,14}$. Zhou et al. ${ }^{4}$ showed that adenosine receptor agonist 5'-N-ethyl carboxamide adenosine reduced leukocyte activation in the intestinal submucosal venules and improved capillary perfusion within the intestinal muscular layers, identifying a protective role for extracellular adenosine signaling in intestinal IR injury.

It has been described ${ }^{23}$ that IPC results in the release of substances such as adenosine, bradykinin, endogenous opioids, and other growth factors which activate cardioprotective pathways against heart IR. Once the cell has been preconditioned, these pathways are activated at reperfusion, preventing the release of proapoptotic factors that trigger cell death. The remote IPC, when ischemia cycles of a distant region or organ have a similar protective effect on myocites subjected to ischemia ${ }^{24}$. In our experiments, the heart injury was distally induced, by intestinal IR, as well the preventive action, the remote IPC. The remote IPC protective effect was probably potentialized by exogenous $\mathrm{AD}$, enhancing the availability of AD generated by IPC.

Recent study first verified that extracellular vesicles, containing proteins, mRNAs and microRNAs, released from the heart after IPC are necessary for cardioprotection by RIPC, evidencing the importance of vesicular transfer mechanisms in remote cardioprotection ${ }^{25}$. Our study identified morphological protection induced by IPC and AD and further studies are necessary to clarify the involved mechanisms.

\section{Conclusion}

Heart tissue showed lesions because of intestinal ischemia reperfusion. IPC as well as AD protect the heart against reperfusion injury, in better way when associate to each other. 


\section{References}

1. Reilly PM, Schiller HJ, Bulkley GB. Pharmacologic approach to tissue injury mediated by free radicals and other reactive oxygen metabolites. Am J Surg. 1991 Apr; 161:488-503. PMID 2035771.

2. Belzer FO, Southard JH. Principles of solid-organ preservation by cold storage. Transplantation. 1998; 45:670-3. PMID 3282347.

3. Abu-Elmagd $\mathrm{K}$, Bond G. Gut failure and abdominal visceral transplantation. Proc Nutr Soc. 2003 Aug;62:727-37. PMID 14692608 .

4. Zhou J, Zimmermann K, Krieg T, Soltow M, Pavlovic D, Cerny V, Lehmann C. Adenosine receptor activation improves microcirculation in experimental intestinal ischemia/reperfusion. Clin Hemorheol Microcirc. 2014 Jun 2. [Epub ahead of print] PubMed PMID: 24889778.

5. Liu Y, Ma L. Which is more important in the potential interference on cardioprotection by remote ischemic preconditioning: $\beta$-blockers or anesthetic choice? J Thorac Cardiovasc Surg. 2013 Nov;146(5):1305-6. PubMed PMID: 24128912. doi: 10.1016/j. jtcvs.2013.04.047.

6. Sivaraman V, Yellon DM. Pharmacologic therapy that simulates conditioning for cardiac ischemic/reperfusion injury. J Cardiovasc Pharmacol Ther. 2014 Jan;19(1):83-96. doi: 10.1177/1074248413499973. Epub 2013 Sep 13. PubMed PMID: 24038018.

7. Brandão SC, Taha MO, Fagundes DJ, Souccar C, Lapa AJ, Pias VMS.- Alpha -Tocopherol in the hypothermic preservation on the rat small Intestinal. Transplant Proc. 2002; 24:1092-4. PubMed PMID: 12072285.

8. Taha MO, Fraga MM, Fagundes DJ, Jurkiewicz A, Caricati-Neto A. Ascorbic acid prevents autonomic dysfunction of rats jejune submitted to cold ischemic preservation for transplant. Transplant Proc. 2004 Mar;36(2):289-92. PubMed PMID: 15050136.

9. Taha MO, Fraga MM, Fagundes DJ, Jurkiewicz A, Caricati-Neto A. Effect of alopurinol on autonomic dysfunction in rat jejunal segments exposed to cold ischemic preservation for transplantation. Transplant Proc. 2004 Mar; 36(2):293-5. PubMed PMID: 15050137.

10. Taha MO, Fraga M, Guimarães FA, Jurkiewicz A, Caricati-Neto A. Atenolol attenuates autonomic dysfunction of rat jejune submitted to cold ischemic preservation. Transplant Proc. 2006 Jul-Aug; 38(6): 1784-8. PubMed PMID: 16908280.

11. Taha MO, Fraga M, Guimarães FA, Jurkiewicz A, Caricati-Neto A. Autonomic dysfunction of rat jejune submitted to cold ischemic preservation is prevented by heparin. Transplant Proc. 2006 JulAug; 38(6): 1779-83. PubMed PMID: 16908279.

12. Ozacmak VH, Sayan H. Pretreatment with adenosine and adenosine A1 receptor agonist protects against intestinal ischemia-reperfusion injury in rat. World J. Gastroenterol. 2007 Jan 28;13(4):538-47. PMID 17278219. doi: 10.3748/wjg.v13.i4.538

13. Headrick JP, Lasley RD. Adenosine receptors and reperfusion injury of the heart. Handb Exp Pharmacol 2009; (193): 189-214. PMID 19639283. doi: 10.1007/978-3-540-89615-9_7.

14. McIntosh VJ, Lasley RD. Adenosine receptor-mediated cardioprotection: are all 4 subtypes required or redundant? J Cardiovasc Pharmac Therap. 2012; 17(1):21-33. PMID 19639283 doi: $10.1177 / 1074248410396877$

15. Pan SJ, Li LR. Adenosine A2 receptors are involved in the activation of ATP-sensitive $\mathrm{K}+$ currents during metabolic inhibition in guinea pig ventricular myocytes. Can J Physiol Pharmacol. 2011 Mar; 89(3):187-96. PMID 21423292. doi: 10.1139/Y11-010.

16. Gazoni LM, Walters DM, Unger EB, Linden J, Kron IL, Laubach VE. Activation of A1, A2A, or A3 adenosine receptors attenuates lung ischemia-reperfusion injury. J Thorac Cardiovasc Surg. 2010 Aug;
140(2):440-6. PMID 20398911. doi: 10.1016/j.jtcvs.2010.03.002

17. Abrahão MS, Montero EF, Junqueira VB, Giavarotti L, Juliano Y, Fagundes DJ. Biochemical and morphological evaluation of ischemia-reperfusion injury in rat small bowel modulated by ischemic preconditioning. Transplant Proc. 2004 May; 36(4):860-2. PubMed PMID: 15194294. doi 10.1016/j.transproceed.2004.03.046

18. Jácome DT, Abrahão MS, Morello RJ, Martins JL, Medeiros AC, Montero EF. Different intervals of ischemic preconditioning on small bowel ischemia-reperfusion injury in rats. Transplant Proc. 2009 Apr;41(3):827-9. PubMed PMID: 19376363.doi: 10.1016/j. transproceed.2009.01.071.

19. Beheshtian A., Demehri S., Kiumehr S. Salmasi AH, Nezami BG, Rahimpour S, Amanpour S, Rabbani S, Mohagheghi MA, Dehpour AR. ATP-sensitive potassium channels mediate the anti-ischemic properties of ischemic and pharmacologic preconditioning in rat random-pattern skin flap. Ann Plast Surg. 2006 Jul; 57(1):94-9. PubMed PMID: 16799317.

20. Cutrn JC, Perrelli MG, Cavalieri B, Peralta C, Roselló-Catafau J, Poli G. Microvascular disfunction induced by reperfusion injury and protective effect of ischemic preconditioning. Free Radic Biol Med. 2002 Nov 1; 33(9):1200-8. PubMed PMID: 12398928. doi: 10.1016/S0891-5849(02)01017-1

21. Um JW, Matthews JB, Song JC, Mun EC. Role of protein kinase $\mathrm{C}$ in intestinal ischemic preconditioning. J Surg Res. 2005 Apr;124(2):289-96. PMID: 15820260. doi:10.1016/j. jss.2004.10.011

22. Candilio L, Malik A, Hausenloy DJ. Protection of organs other than the heart by remote ischemic conditioning. J Cardiovasc Med (Hagerstown). 2013 Mar;14(3):193-205. PubMed PMID: 23079610. doi: 10.2459/JCM.0b013e328359dd7b

23. Sivaraman V, Yellon DM. Pharmacologic therapy that simulates conditioning for cardiac ischemic/reperfusion injury. J Cardiovasc Pharmacol Ther. 2014 Jan;19(1):83-96. PubMed PMID: 24038018. doi: $10.1177 / 1074248413499973$.

24. Hausenloy DJ, Yellon DM. Remote ischaemic preconditioning: underlying mechanisms and clinical application. Cardiovasc Res. 2008 Aug 1;79(3):377-86. PMID: 18456674. doi: 10.1093/cvr/ cvn114.

25. Giricz Z, Varga ZV, Baranyai T, Sipos P, Pálóczi K, Kittel Á, Buzás EI, Ferdinandy P. Cardioprotection by remote ischemic preconditioning of the rat heart is mediated by extracellular vesicles. J Mol Cell Cardiol. 2014 Mar;68:75-8. PubMed PMID: 24440457. doi: 10.1016/j.yjmcc.2014.01.004.

\section{Correspondence:}

Murched O. Taha

Rua JoaquimTávora, 1599/161 andar 04015-003 São Paulo - SP Brasil,

Tel.: (55 11)5084-0100

Fax: (55 11)5571-0233

taha@uol.com.br

Financial source: Sao Paulo Research Foundation (FAPESP)

${ }^{1}$ Research performed at Operative Technique and Experimental Surgery Division, Department of Surgery and Department of Biochemistry and Pharmacology, Federal University of Sao Paulo (UNIFESP), Brazil. 